\title{
Syntactic complexity in English as a lingua franca academic writing
}

\author{
$\mathrm{Wu}$, Xue
}

2020-01

Wu , X , Mauranen , A \& Lei , L 2020 , ' Syntactic complexity in English as a lingua franca academic writing ' , Journal of English for Academic Purposes , vol. 43 , 100798 . https://doi.org/10.1016/j.jeap.2019

http://hdl.handle.net/10138/319569

https://doi.org/10.1016/j.jeap.2019.100798

cc_by_nc_nd

acceptedVersion

Downloaded from Helda, University of Helsinki institutional repository.

This is an electronic reprint of the original article.

This reprint may differ from the original in pagination and typographic detail.

Please cite the original version. 


\section{Journal Pre-proof}

Syntactic complexity in English as a lingua franca academic writing

Xue Wu, Anna Mauranen, Lei Lei

PII: $\quad$ S1475-1585(18)30525-3

DOI: $\quad$ https://doi.org/10.1016/j.jeap.2019.100798

Reference: JEAP 100798

To appear in: Journal of English for Academic Purposes

Received Date: 3 October 2018

Revised Date: 4 September 2019

Accepted Date: 24 September 2019

Please cite this article as: Wu, X., Mauranen, A., Lei, L., Syntactic complexity in English as a lingua franca academic writing, Journal of English for Academic Purposes (2019), doi: https://doi.org/10.1016/ j.jeap.2019.100798.

This is a PDF file of an article that has undergone enhancements after acceptance, such as the addition of a cover page and metadata, and formatting for readability, but it is not yet the definitive version of record. This version will undergo additional copyediting, typesetting and review before it is published in its final form, but we are providing this version to give early visibility of the article. Please note that, during the production process, errors may be discovered which could affect the content, and all legal disclaimers that apply to the journal pertain.

(C) 2019 Published by Elsevier Ltd. 


\section{Syntactic complexity in English as a lingua franca academic writing}

Xue $\mathrm{Wu}^{\mathrm{a}}{ }^{\text {, }}$, Anna Mauranen ${ }^{\mathrm{b}}$, Lei Lei ${ }^{\mathrm{c}}$

${ }^{\text {ac }}$ School of Foreign Languages, Huazhong University of Science and Technology, 1037 Luoyu Rd., Wuhan, China

${ }^{\mathrm{b}}$ Department of Modern languages, University of Helsinki, Finland

*Corresponding author

E-mail addresses: wuxue@hust.edu.cn (X. Wu), anna.mauranen@helsinki.fi (A. Mauranen), leileicn@126.com (L. Lei) 


\section{Syntactic complexity in English as a lingua franca academic writing}

Abstract: This study complements previous research on linguistic features of English as a lingua franca (ELF) from a syntactic complexity perspective. Specifically, the present study seeks to find out how ELF users express meaning relations in research articles using different syntactic structures. The same syntactic phenomena are also analyzed in comparable texts written in American English (AmE) to see in which way ELF writing is shaping research writing in English. Our findings show that the values of nine indices from four syntactic complexity dimensions in ELF research articles are significantly different from those in comparable AmE research articles. ELF authors use longer sentences to improve communication efficiency, and more coordinate phrases and complex nominals to enhance clarity and to increase explicitness. In addition, considering phrasal complexity, ELF research articles show greater reliance on nominal phrases in comparison to AmE articles. In other words, the convention of a nominal style is valued in ELF academic written discourse. These features of syntactic complexity illustrate writers' handling of two competing goals, explicitness and conciseness, in the ELF academic writing. This study is significant in that it offers insights to the description of the emerging use of ELF in academic written discourse.

Key words: syntactic complexity, English as a lingua franca, academic writing

\section{Introduction}

Against the backdrop of economic globalization and academic mobility, the use of English as a global lingua franca has become a normal part of life for large numbers of people in and outside academia. For most of its speakers, English is not their first language, but estimates have it that second-language speakers outnumber first-language speakers by a ratio of 4 to 1 (Crystal, 2003). English as a lingua franca (henceforth ELF) is thus the predominant means of communication in English today. Research into ELF began by analyzing spoken interactions (Firth 1996; House 2009; Jenkins, 2000), which still accounts for most of the publications in the field (Cogo \& Dewey, 2012). The compilation of spoken ELF corpora such as the corpus of English as a lingua franca in Academic settings (ELFA) (ELFA, 2008; Mauranen, 2003) and the general Vienna-Oxford International Corpus of English (VOICE) (Seidlhofer, 2004) has further helped the analysis and description of spoken ELF. For instance, Mauranen (2012) has investigated a number of features of ELF speech. Another example is Seidlhofer and Widdowson (2009) who analyze ELF idiomaticity. The predominance of spoken language research is also true of academic ELF discourses (Hynninen, 2011; Jenkins, 2011; Mauranen, 2009). By contrast, written academic ELF has received far less attention hitherto.

Academic writing among speakers of other first languages than English has been widely studied but from an ESL (English as a second language) or EFL (English as a foreign language) viewpoint (Ädel et al., 2012; Chang \& Schleppegrell, 2011; Chen \& Baker, 2010; Hyland, 2004; Ingvarsdóttir \& Arnbjørnsdottir, 2013; Tang, 2012). Previous studies (especially those published in Journal of English for Academic Purposes and Journal of Second Language Writing) have provided valuable information on English beyond the 'inner circle'. Corpus analyses have shown 
that ESL or EFL academic writing differs from that by ENS (English native speakers) in many respects such as syntactic and discourse features (Granger, 1997; Granger \& Tyson, 1996). Granger and Tyson (1996) have identified relative overuse/underuse and divergent uses in semantic, stylistic, and syntactic properties of individual connectors in EFL academic writing in comparison with ENL (English as the native language) academic writing. Granger (1997) finds that EFL academic writing had fewer participle clauses, which she considered a stylistic deficiency. Martínez (2005) reports overuse, underuse and phraseological choices of first person pronouns in research articles written by EFL speakers. It should be noted that most studies on ESL or EFL academic writing take ENL texts as the unquestioned language norm, thus depicting ESL or EFL texts as suffering from underuse, overuse or misuse of linguistic items.

However, those previous studies have overlooked ESL or EFL speakers' role as ELF users rather than learners, ignoring their professional status in the global context in favor of a projected 'eternal learner' position. The purpose of the present study is to extend the ELF perspective to academic research articles aimed at publication for an international audience. These are increasingly important to anyone aspiring to an academic career, or advancement in it, not only those who seek special international recognition. We focus specifically on syntactic complexity in research articles in this study. Syntactic complexity is an intriguing issue in relation to ELF. Generally, language contact and lingua francas are expected to lead to syntactic simplification (Thomason 2001; Trudgill 2011). In spoken ELF, however, Ranta (2013) has found evidence of extended use of complex syntactic structures such as progressive -ing and other verb phrases. In written ELF, such issues have rarely been addressed.

We begin our research by detecting indicators of syntactic complexity in ELF research articles using quantitative analysis, and then move on to qualitative investigation of how these observed features relate to meaning relations in our text samples.

\subsection{ELF in academic writing}

Publishing in high-profile international journals plays a critical role in scholars' academic life (Hyland, 2015) because it has become an increasingly widely used measure of academic performance. Academic publishing has recently undergone a spurt of fast growth worldwide. It is estimated that every year more than 1.5 million research articles are produced by six million academics from 17,000 universities and research organizations across the globe (Bjork et al. , 2009; Hyland, 2016). Under the pressure of 'publish or perish', academics around the world vitalize their professional life by publishing more research articles in high profile international journals (most of which are printed in English) (Cargill \& O'Connor, 2006; Hall, 2011). In this case, academic publishing involves authors, editors, reviewers and readers with different first languages. That is, academic writing submitted to or published in international journals is for an international rather than an ENL community. Therefore, exploring the use of ELF in academic writing may shed light on intriguing questions such as what is distinctive about ELF.

According to statistics, more than $90 \%$ of the high profile journals indexed in International Scientific Indexing (ISI) database are printed in English (Hyland, 2015). The prevalence of English in academic publishing has distinct advantages. First, as a common language, it facilitates international research collaboration. Second, it enables authors from diverse cultural and linguistic 
backgrounds to foster a worldwide dissemination and exchange of new scientific knowledge. However, the vast majority of studies in English research writing has focused either on native speakers of English or on comparisons between English mother-tongue writers and others (Swales, 1990; Granger \& Tyson, 1996; Martínez, 2005; Mancilla et al., 2015), with the explicit or implicit point of departure that any differences between these indicate that speakers of other native languages have a problem and should be taught to adopt the ways of ENL writers. There is thus a clear need for more emphasis in ELF research on the nature of written ELF academic discourse, as Ingvarsdóttir and Arnbjørnsdottir (2013) point out. Additionally, an ELF perspective can mitigate the effect of linguistic injustice which has been a concern in an increasing body of literature (Flowerdew, 2008; Hyland, 2016; Politzer-Ahles et al., 2016). In this scenario, it is important to describe what ELF brings to international academic writing.

Some studies have already addressed the use of English in written ELF. For instance, Lorés-Sanz (2016) gains support for her hypothesis that the rhetorical level of research article abstracts has been reshaped by non-Anglophone authors. By sampling 66 abstracts from research articles in sociology by ELF authors from 2012 to 2014, Lorés-Sanz (2016) has explored the rhetorical structures with the help of Swales' (1990) moves. In addition to the conventional structures, she suggests three variants of hybrid structure in ELF research journal abstracts: detailed description of one move, simple structure intertwined with method, aim and results, and taking unusual moves such as conclusion and method as a point of departure. Another example is Mur-Dueñas (2015) who examines lexical-grammatical innovations in ELF academic writing through an analysis of the evaluative it-clause. Her research is based on a corpus of 48 research articles by scholars with a variety of linguacultural backgrounds from international journals in the discipline of business management during 2002-2010. Mur-Dueñas (2015) finds that research articles by ELF authors contain a larger number and wider range of adjectives in evaluative $i t$-clauses. These studies are significant in that they foreshadow the innovative use of English in written academic context. That is, they show how ELF authors adapt and blend the use of English in international written academic communication. Yet, there are at least three limitations in the previous research which need to be addressed in future studies. In the first place, more scientific domains should be represented in the data. Second, although published research articles are ELF texts in the sense that they are produced and read by authors, editors, reviewers and readers with diverse cultural backgrounds, unedited research articles can best represent the natural ELF use. Last, a larger and better-balanced corpus of ELF academic writing texts is needed for more reliable and precise analysis.

\subsection{Syntactic complexity in academic writing}

The conceptualization of complexity in language is complex and can be approached from different aspects (Bulté \& Housen, 2012; Pallotti, 2014; Ortega, 2003). For instance, in SLA research, syntactic complexity is used as an indicator of learners' language proficiency (Crossley \& McNamara, 2014; Wolfe-Quintero et al., 1998), to measure language proficiency (Ferris, 1994; Ortega, 2003) and to test effectiveness of specific pedagogical intervention (Ellis, 2009; Ong \& Zhang, 2010). The conceptualization of syntactic complexity in this study is based on Pallotti's (2014) stylistic syntactic complexity which is measured by 'looking at the number of 
interconnected constituents in a structure'. Those interconnected constituents can be length of phrase, number of phrases per clause and number of clauses per unit (Neary-Sundquist, 2017).

Previous studies have indeed detected difference in syntactic complexity with regard to length of production unit, amount of subordination, amount of coordination, and degree of phrasal complexity between writing by native speakers (NS) and non-native speakers (NNS) (Ai \& Lu, 2013; Foster \& Tavakoli, 2009; Mancilla et al., 2015). However, findings from these studies have not been consistent on account of genre differences. In online discussions, NNS use more coordination and complex phrases but less subordination than NS do, although high level NNS writing approaches NS writing with respect to the amount of subordination (Mancilla et al., 2015). In students' writing at college level, NNS produce shorter clauses, sentences and T-units, less subordination and fewer nominal phrases than NS do (Ai \& Lu, 2013).

Handling syntactic complexity is a challenging task considering the two competing goals in academic writing: explicitness and conciseness (Biber \& Gray, 2010; Sawyer et al., 2008; Zinsser, 1988). It should be noted that the notion of explicitness in the present study is adopted from Mauranen (1993) who suggests that an explicit message is overt and straightforward, thus easy to read and process. On the one hand, complex syntactic structures such as nominal phrases in sentences and T-units meet the goal of conciseness in academic writing. Previous research found that academic writing is characterized by longer sentences and T-units and large amounts of subordinations, and nominalizations (Brown \& Yule, 1983; Halliday \& Martin, 2003; Hughes, 1996; O' Donnell, 1974). These syntactic structures make the writing compact by reducing redundancy. On the other hand, complex syntactic structures which are compressed may reduce the clarity of the intended meaning, which goes against the goal of explicitness in academic writing. For instance, Biber and Gray (2010) argue that the extensive phrasal complexity, especially noun-noun phrases, makes the expression of logical relation among elements implicit rather than explicit in academic writing. In addition, complex syntactic structures may hinder the readability of research articles (Otto et al., 2011; Rottensteiner, 2010; Dolnicar \& Chapple, 2015).

The focal texts in this study are produced by writers who use English as a lingua franca, and therefore it is important to take into account what we might expect from their writing. ELF is a complex form of language contact, what we might call 'second-order language contact' (Mauranen 2012, 2017), that is, the contact between 'similects', which in themselves result from language contact between speakers' L1s and a given L2 that they have all learned (Mauranen 2017). The syntactic consequences of language contact in earlier research usually point to syntactic simplification (Thomason 2001; Trudgill 2009, 2011). Two principal reasons for simplification are singled out by Trudgill (2011): (1) language contact and (2) adult second language learning. Both apply to ELF. Kusters (2003) investigates several language groups in different sociolinguistic circumstances and argues that languages used as lingua francas have undergone simplification, whereas languages used in closed speech communities tend to retain complexity. This supports the suggestion made by Milroy and Milroy (1985). We might therefore assume that syntax in ELF would on the whole be simplified in comparison to Standard English.

Altogether, then, we have two possible outcomes for research into syntactic complexity in ELF research articles: either the effect of language contact and the genre-based demand for explicitness and clarity make them simpler than corresponding L1 texts, or the demands of the 
genre counteract these demands, and in effect they retain similar levels of complexity. In the next section, we set out to explore the matter further.

\subsection{Research questions}

Specifically, this study centered on the following two research questions:

(1) What are the features of syntactic complexity in ELF research articles, taking the American English forms into account?

(2) How do these features of syntactic complexity influence the meaning relations in ELF research articles?

\section{Method}

\subsection{Data}

This study draws research article samples from SciELF corpus and Corpus of Contemporary American English (COCA).

SciELF, one of the three subcorpora (the other two are $\mathrm{PhD}$ examiner reports and academic research blogs) in WrELFA corpus (Written English as a Lingua Franca in Academic settings) (WrELFA, 2015), contains 150 unedited research articles, totaling 759k words. Science (category 'Sci') and social sciences and humanities (category 'SSH') are represented as two broad disciplinary categories. The Sci category includes research articles from natural sciences, medicine and agriculture \& forestry. The SSH category covers social sciences, humanities and behavioral sciences. The authors are from ten different countries and regions around the world. That is, SciELF affords a good diversity of the authors' first languages. These research articles have not been professionally proofread nor checked by an English native speaker. Hence, the SciELF corpus represents the ELF used naturally in written scientific communication.

COCA (COCA, 2015; Davies, 2010) comprises 520 million running words and is evenly divided between five genres of spoken, fiction, popular magazines, newspapers, and academic journals. We randomly sampled research articles from the academic portion which contains 103 million words from nearly 100 different peer-reviewed journals. The sampled research articles are of equal amount and are from similar domains as those from SciELF to guarantee a reasonable comparison. We chose research articles from COCA for the following three reasons. Firstly, it is robust enough to look at the syntactic constructions in research articles as Davies (2013) argued that the academic portion in COCA 'is the largest traditional corpus of academic English'. Secondly, again as Davies (2013) has rightly pointed out that in comparison to other sources of research articles such as Google Scholar, COCA allows a retrieval of a wide range of constructions which might provide insight into academic English. Last, given that the sampled research articles in COCA are published journal articles, COCA constitutes an appropriate corpus as well-accepted use of American English (henceforth AmE) for comparing ELF research articles in SciELF 
Table 1 presents a summary of the data in the present study. Since published research articles in COCA are relatively shorter than the unpublished ones in SciELF, this may account for differences in syntactic complexity results, especially in length.

Table 1

Summary of data.

\begin{tabular}{|c|c|c|c|c|c|}
\hline \multicolumn{2}{|c|}{ Category / domain } & \multirow{2}{*}{$\begin{array}{l}\text { SciELF (texts) } \\
59\end{array}$} & \multirow{2}{*}{$\begin{array}{l}\text { SciELF(tokens) } \\
270,986\end{array}$} & \multirow{2}{*}{$\begin{array}{l}\text { COCA(texts) } \\
59\end{array}$} & \multirow{2}{*}{$\begin{array}{l}\text { COCA(tokens) } \\
241,571\end{array}$} \\
\hline & Natural science & & & & \\
\hline \multirow[t]{3}{*}{ Sci } & Medicine & 16 & 61,713 & 16 & 58,301 \\
\hline & Agriculture \& forestry & 3 & 11,320 & 3 & 9,646 \\
\hline & Social science & 33 & 197,958 & 33 & 147,724 \\
\hline \multirow[t]{2}{*}{ SSH } & Humanities & 23 & 154,678 & 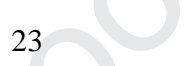 & 115,348 \\
\hline & Behavioral science & 16 & 93,016 & 16 & 79,745 \\
\hline \multicolumn{2}{|c|}{ Total } & 150 & 789,671 & 150 & 652,335 \\
\hline
\end{tabular}

\subsection{Measures of syntactic complexity}

A wealth of syntactic complexity measures has been used in previous literature even though criticism pertaining to the construct definition and the theoretical underpinnings of measurements remains (Norris \& Ortega 2009; Bulté \& Housen 2014, 2018). Yet, this wide range of measures fails to yield a multidimensional description of syntactic complexity in English writing. The reason, as pointed out by Bulté and Housen (2018) is that previous studies, especially those on L2 writing, take a reductionist approach in which they only use the 'popular' measures (for example, mean length of T-unit, subordination ratios) but eschew syntactic complexity at other levels. In order to get a fuller understanding of syntactic complexity in ELF academic writing, the present study adopts 14 indices from the L2 syntactic complexity analyzer (henceforth L2SCA) developed by Dr. Lu Xiaofei ( $\mathrm{Lu}, 2009,2010)$. In addition to the overall sentence complexity, the 14 indices also cover four other dimensions of syntactic complexity: length of production, amount of subordination, amount of coordination, and phrasal complexity. Table 2 shows a summary of the 14 indices and their corresponding codes and formula.

The values of the 14 indices of syntactic complexity in ELF and AmE writing are calculated respectively with L2SCA. Then, a two independent-samples Mann-Whitney $U$ test is run to determine whether there is significant difference in the mean complexity values among the ELF and AmE data. We choose Mann-Whitney U-test rather than a t-test because the values of the syntactic measures in both ELF and AmE research articles are a non-normal distribution. Once the differences in syntactic complexity are identified statistically, qualitative analysis is carried out to investigate how the different syntactic complexity features influence the meaning relation by examples extracted from the ELF and AmE research articles. 
Table 2

Syntactic complexity measures investigated (modified from Ai and Lu (2013)).

\begin{tabular}{|c|c|c|}
\hline Measure & Code & Formula \\
\hline \multicolumn{3}{|l|}{ Length of production unit } \\
\hline Mean length of sentence & MLS & \#of words/\# of sentences \\
\hline Mean length of T-unit & MLT & \#of words/\# of T-units \\
\hline Mean length of clause & MLC & \#of words/\# of clauses \\
\hline \multicolumn{3}{|l|}{ Amount of subordination } \\
\hline Clauses per T-unit & $\mathrm{C} / \mathrm{T}$ & \#of clauses/\# of T-unit \\
\hline Complex T-unit ratio & $\mathrm{CT} / \mathrm{T}$ & \#of complex T-units /\# of T-units \\
\hline Dependent clauses per clause & $\mathrm{DC} / \mathrm{C}$ & \#of dependent clauses/\# of clauses \\
\hline Dependent clauses per T-unit & $\mathrm{DC} / \mathrm{T}$ & \#of dependen $\mathrm{t}$ clauses/\# of T-units \\
\hline \multicolumn{3}{|l|}{ Amount of coordination } \\
\hline Coordinate phrases per clause & $\mathrm{CP} / \mathrm{C}$ & \#of coordinate phrases/\# of clauses \\
\hline Coordinate phrases per T-unit & $\mathrm{CP} / \mathrm{T}$ & \#of coordinate phrases/\# of T-units \\
\hline T-unit per sentence & $\mathrm{T} / \mathrm{S}$ & \#of T-units/\# of sentences \\
\hline \multicolumn{3}{|l|}{ Phrasal complexity } \\
\hline Complex nominals per clause & $\mathrm{CN} / \mathrm{C}$ & \#of complex nominals/\# of clauses \\
\hline Complex nominals per T-unit & $\mathrm{CN} / \mathrm{T}$ & \#of complex nominals/\# of T-units \\
\hline Verb phrases per T-unit & $\mathrm{VP} / \mathrm{T}$ & \#of verb phrases/\# of T-units \\
\hline \multicolumn{3}{|l|}{ Overall sentence complexity } \\
\hline Clauses per sentence & $\mathrm{C} / \mathrm{S}$ & \#of clauses/\# of sentences \\
\hline
\end{tabular}

\subsection{Qualitative analysis of complex syntactic structures}

For the second research question, a qualitative analysis was carried out to find out how specific features of syntactic complexity influence the meaning relations in ELF research articles. For practical reasons, we randomly selected and compared the texts of 30 research articles from each of the ELF and AmE groups for the qualitative analysis. The articles cover both natural science and social science domains, and the authors in the ELF group represent ten different first languages (Finnish, Czech, French, Chinese, Spanish, Russian, Swedish, Italian, Portuguese, and Romanian). The significant differences in syntactic complexity measures between ELF and AmE 
research articles form the locus for qualitative analysis in this study. Specifically, the qualitative analysis aims to describe what the featured uses of syntactic complexity in ELF research articles entail in the process of meaning construction. With this focus, we seek to obtain a clearer picture as to how complex syntactic structures influence the explicitness of a message in ELF research articles.

The following steps were taken to carry out for qualitative analysis. In the very beginning, one of the authors and a research assistant (both hold doctor's degree in applied linguistics) who had been informed of the quantitative results received training about syntactic complexity measures used in the present study. After the training, an inter-coder agreement was reached (Intraclass correlation coefficient $=0.82$ ). The two researchers then individually started holistic reading of the randomly chosen 30 research articles from each data set, and recorded the structures which may signify syntactic complexity while reading. After the holistic reading, the two researchers compared notes and drafted a list of complex syntactic structures that distinguish the two data sets. Last, concordance lines of these distinctive complex syntactic constructions were retrieved, coded, manually checked and analyzed to examine how they influence meaning relations in different research articles.

\section{Results and discussion}

This section fully sketches the results and discussion with regard to the two research questions introduced in section 1.3.

\subsection{Research question 1}

The focus of the first research question in this study is the features of syntactic complexity in ELF research articles, taking the AmE forms into account. The Mann-Whitney U-test results are summarized in Table 3 and Table 4. Table 3 shows that the mean ranks of the ELF group are higher than those in AmE group for 10 out of the 14 syntactic complexity measures (i.e. all but $\mathrm{C} / \mathrm{T}, \mathrm{CT} / \mathrm{T}, \mathrm{DC} / \mathrm{T}$, and VP/T). In the ELF group, the mean ranks of all measures related to the length of production unit and amount of coordination are higher than those in AE group. In other words, ELF users employed relatively longer sentences, T-units and clauses, and more coordinate phrases in each clause and each T-unit in research articles than their AmE counterparts. Table 4 shows that there are statistically significant differences $(p<0.05, r>0.1)$ in the values of 9 out of the 14 measures (i.e. all but five measures, MLT, CT/T, DC/C, DC/T, and C/S) between the EFL and the AmE groups.

The quantitative results show that although the overall sentence complexity (measured using $\mathrm{C} / \mathrm{S}$ ) shows no difference, significant differences do exist across all the four dimensions of syntactic complexity between ELF and AmE research articles.

For length of production unit, the mean lengths of sentences and clauses in ELF group are significantly longer than those in AmE group. No significant difference is detected in the mean length of T-units. The finding that sentences and clauses are longer in ELF research articles supports previous research which suggest that longer sentences and longer clauses are 
characteristic of academic writing (O' Donnell, 1974; Brown \& Yule, 1983). However, as Ai and Lu (2013) shows, in comparison to NS university students, NNS university students (who were Chinese English learners) use significantly shorter sentences, T-units and clauses in their writing. It can be seen that the ELF scientific writers use English differently from both learners of English and AmE users. On the one hand, they produce long sentences, T-units and clauses, as AmE writers do. On the other hand, they write sentences and clauses which are even longer than those of AmE writers. One of the reasons might be that published research articles in COCA are relatively tighter in writing than the unpublished ones in SciELF. The other possible reason might be that longer sentences, which are often embedded with clauses, T-units and phrases, may facilitate presentation of meaning (Keen, 2004; Li \& Ge, 2009; Wright, 2008) and communication of information. We will return to this discussion of the function of long sentences in section 3.2.

In terms of amount of subordination, all but the measure $\mathrm{C} / \mathrm{T}$ show no significant difference between the two groups. Specifically, ELF writers use similar proportion of complex T-units and dependent clauses as AmE writers do in research articles, but they use significantly fewer clauses per T-unit than their AmE counterparts. The results in this study show that ELF writers generally use the same amount of subordination as the AmE writers, with measure of $\mathrm{C} / \mathrm{T}$ being the only difference. Hyland (2002) mentions that more subordination in academic writing was a widespread perception. It seems that ELF scholars adhere to this perception as well since they use comparable amount of subordination to that by native speakers.

With regard to the amount of coordination, ELF writers use significantly more coordination at both phrasal and sentential levels than AmE writers. As an intra-sentential structural device, coordination conjoins the same kind of syntactic patterns and performs special functions in academic writing (Bell, 2007; Halliday \& Hasan, 2014; Jeremy, 1978). Hence, the significantly higher use of coordination can be regarded as another feature in ELF research articles.

Finally, as for the aspect of phrasal complexity, the proportions of complex nominal and verb phrases in ELF and AmE groups are noticeably different. ELF writers use significantly more complex nominals but significantly fewer verb phrases than AmE writers. Since many studies have argued about the nominal and verbal style of academic writing (Biber \& Gray, 2010; Halliday \& Martin, 2003; Wells, 1960), the dramatically different uses of complex nominals and verb phrases are considered as the third feature in ELF research articles.

Table 3

Ranks of values of the 14 syntactic measures in EFL and AmE groups.

\begin{tabular}{llllll}
\hline & & ELF_AmE & N & Mean Rank & Sum of Ranks \\
\hline \multirow{2}{*}{ Overall sentence complexity } & C/S & ELF & 150 & 155.36 & 22838.00 \\
& & AmE & 150 & 139.64 & 20527.00 \\
& & Total & 300 & \\
\hline & MLS & ELF & 150 & 181.29 & 26649.00 \\
& & AmE & 150 & 113.71 & 16716.00 \\
\cline { 2 - 6 } & & Total & 300 & \\
\hline
\end{tabular}




\begin{tabular}{|c|c|c|c|c|c|}
\hline \multirow{5}{*}{ Length of production unit } & & $\mathrm{AmE}$ & 150 & 140.29 & 20622.00 \\
\hline & & Total & 300 & & \\
\hline & MLC & ELF & 150 & 168.77 & 24809.00 \\
\hline & & AmE & 150 & 126.23 & 18556.00 \\
\hline & & Total & 300 & & \\
\hline \multirow{12}{*}{ Amount of subordination } & $\mathrm{C} / \mathrm{T}$ & ELF & 150 & 130.91 & 19243.50 \\
\hline & & $\mathrm{AmE}$ & 150 & 164.09 & 24121.50 \\
\hline & & Total & 300 & & \\
\hline & $\mathrm{CT} / \mathrm{T}$ & ELF & 150 & 144.89 & 21299.00 \\
\hline & & $\mathrm{AmE}$ & 150 & 150.11 & 22066.00 \\
\hline & & Total & 300 & & \\
\hline & $\mathrm{DC} / \mathrm{C}$ & ELF & 150 & 149.70 & 22005.50 \\
\hline & & $\mathrm{AmE}$ & 150 & 145.30 & 21359.50 \\
\hline & & Total & 300 & & \\
\hline & $\mathrm{DC} / \mathrm{T}$ & ELF & 150 & 142.02 & 20877.00 \\
\hline & & $\mathrm{AmE}$ & 150 & 152.98 & 22488.00 \\
\hline & & Total & 300 & & \\
\hline \multirow{9}{*}{ Amount of coordination } & $\mathrm{CP} / \mathrm{C}$ & ELF & 150 & 164.48 & 24178.50 \\
\hline & & AmE & 150 & 130.52 & 19186.50 \\
\hline & & Total & 300 & & \\
\hline & $\mathrm{CP} / \mathrm{T}$ & ELF & 150 & 159.54 & 23452.00 \\
\hline & & $\mathrm{AmE}$ & 150 & 135.46 & 19913.00 \\
\hline & & Total & 300 & & \\
\hline & $\mathrm{T} / \mathrm{S}$ & ELF & 150 & 172.74 & 25392.50 \\
\hline & & AmE & 150 & 122.26 & 17972.50 \\
\hline & & Total & 300 & & \\
\hline \multirow{8}{*}{ Phrasal complexity } & $\mathrm{CN} / \mathrm{C}$ & ELF & 150 & 182.05 & 26762.00 \\
\hline & & $\mathrm{AmE}$ & 150 & 112.95 & 16603.00 \\
\hline & & Total & 300 & & \\
\hline & $\mathrm{CN} / \mathrm{T}$ & ELF & 150 & 176.00 & 25871.50 \\
\hline & & $\mathrm{AmE}$ & 150 & 119.00 & 17493.50 \\
\hline & & Total & 300 & & \\
\hline & $\mathrm{VP} / \mathrm{T}$ & ELF & 150 & 131.72 & 19362.50 \\
\hline & & $\mathrm{AmE}$ & 150 & 163.28 & 24002.50 \\
\hline
\end{tabular}




\section{Table 4}

Test statistics of values of 14 syntactic complexity measures between EFL and AmE groups

Measure

Code EFL vs. AmE

Mann-Whitney U $\quad$ z $\quad$ P $\quad$ r

Length of production unit

Mean length of sentence

Mean length of T-unit

Mean length of clause

Amount of subordination

Clauses per T-unit

Complex T-unit ratio

Dependent clauses per clause

Dependent clauses per T-unit

Amount of coordination

Coordinate phrases per clause

Coordinate phrases per T-unit

T-unit per sentence

Phrasal complexity

Complex nominals per clause

MLS

5838.000

$-6.814$

.0

.397

00

MLT

9744.000

$-1.455$

.1

.085

46

MLC

7678.000

$-4.290$

00

$\mathrm{C} / \mathrm{T}$

8365.500

$-3.346$

.0

.195

01

CT/T

10421.000

$-.526$

.5

.031

99

DC/C

10481.500

$-.443$

.6

.026

58

DC/T

9999.000

$-1.105$

.2

.064

69

$\mathrm{CP} / \mathrm{C}$

8308.500

$-3.425$

.0

.200

01

$\mathrm{CP} / \mathrm{T}$

9035.000

$-2.428$

.0

.142

15

T/S

7094.500

$-5.090$

.0

.297

00 
00

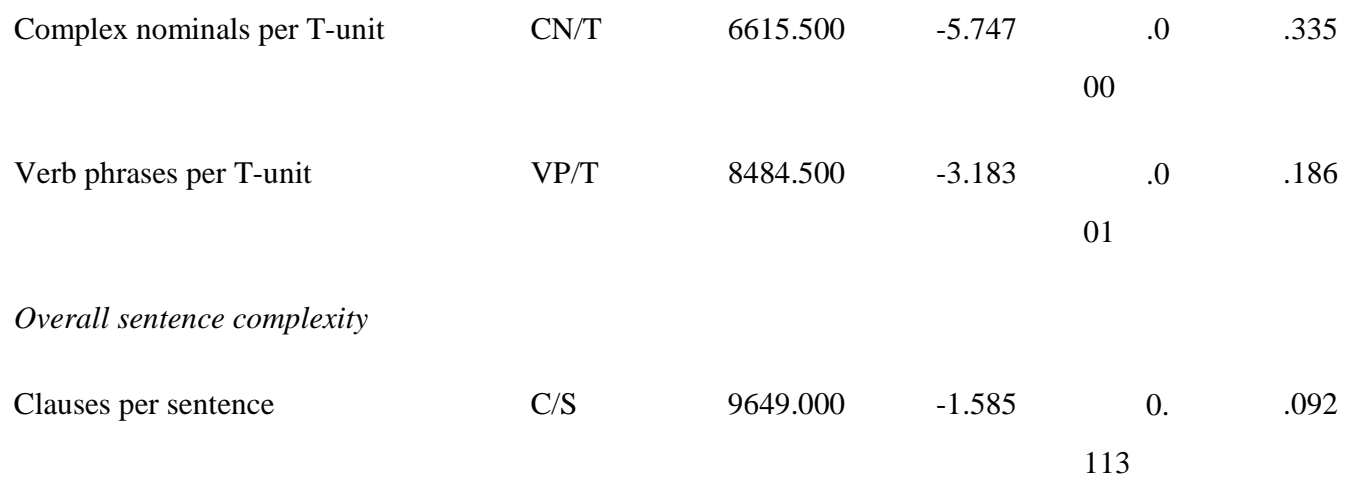

In this section, three features of syntactic complexity in ELF have been identified, including longer sentences and clauses, larger amount of coordination, and more complex nominals. The influence of these features on the meaning relations in ELF research articles will be discussed in 3.2 .

\subsection{Research question 2}

The use of long sentences and clauses may also influence the meaning relations in ELF research articles as Hyland and Tse (2005, p.127) suggest '...elaborated structures are generally preferred as they facilitate the readers' understanding of the text'. In previous literature, most researchers attribute the occurrence of elaborated structures in long sentences to the extensive use of clausal embedding (O’Donnell 1974; Brown \& Yule 1983). The present study also finds a frequent use of clausal embedding in both data sets. Those embedded clauses with expanded expressions may have repercussion in the meaning relations of the whole sentence. As is shown in Example (1) and (2), the sentences become syntactically complex, structurally elaborated and semantically clarified by employing clausal embedding (the underlined ones).

(1) The hypothesis that we have outlined here implies that a long-lasting external influence can be coded by a biological system into a persistent set of data, which can remain silent until it is functionalized by appropriate conditions and provoked by a relevant secondary influence.

(COCA_4119774_natural science)

(2) The entire system with dispersal linked populations fits in to source-sink dynamics theory (Dias 1996; Pulliam 1988), where individual habitats (patches) may represent a source population, which may change after allogeneic succession in to the sink populations and source habitats respectively.

(SciELF_Sci13_natural science)

However, after holistic reading, both researchers gained the impression that ELF writers use longer sentences with more coordinate phrases and complex nominals than AmE writers do. That is, embedding at phrasal level rather than at clausal level accounts for the production of longer sentences in ELF research articles. In order to validate this assertion, coordinate phrases and 
complex nominals in the 60 randomly chosen articles from ELF and AmE groups were retrieved, coded and manually checked. Table 5 shows the coordinate phrases and complex nominals per 1000 sentences in COCA and ELF respectively. It should be noted that in the present study coordinate phrases and complex nominals are defined the same as in $\mathrm{Lu}$ (2010). That is, coordinate phrase refers to coordinate adjective, noun, or verb phrase, and complex nominal refers to a noun plus an adjective, possessive, prepositional phrase, adjective clause, participle, or appositive; a nominal clause; or a gerund or infinitive in subject position. The result in Table 5 confirms the researchers' impression. That is, the frequent use of coordinate phrases (especially coordinate adjectives and coordinate nouns) and complex nominal phrases is one of the elements that account for the long sentences in ELF research articles.

Table 5

Coordinate phrases and complex nominals in COCA and ELF (per 1000 sentences)

\begin{tabular}{lllll}
\hline & & COCA & ELF & $p$ \\
\hline \multirow{2}{*}{ Coordinate phrases } & Coordinate adjectives & 22.57 & 65.21 & .000 \\
& Coordinate verbs & 7.17 & 9.22 & .617 \\
& Coordinate nouns & 49.47 & 207.27 & .000 \\
\hline \multirow{2}{*}{ Complex nominals } & Noun + adjective phrase /possessive phrase & 315.31 & 529.47 & .000 \\
& /prepositional phrase /adjective clause & & & \\
& /participle /appositive & & & \\
& Nominal clause & 43.99 & 116.68 & .000 \\
& A gerund /infinitive in subject position & 45.03 & 85.89 & .000 \\
\hline
\end{tabular}

Context-based concordance analysis further finds that long sentences embedded with phrasal structures may be used to improve communication efficiency, enhance clarity or raise explicitness of meanings in ELF research articles. The practices of syntactic complexity employed in these scenarios are further discussed with examples in the sections below (3.2.1-3.2.3).

\subsubsection{Improve communication efficiency through long sentences.}

Except for the fact that the unpublished ELF research articles are not as tight as the published AmE ones, the use of longer sentences in ELF research articles may be explained as deriving from the intention to improve communication efficiency. The basic communicative goal of scientific research articles, as suggested by Biber \& Conrad (2009), is to convey the results of scientific inquiry. However, the pressure to realize this goal in the age of information explosion has been doubled with the limit of space in written medium. Against this backdrop, the use of long sentence might be a reasonable solution since expanded syntactic structures could be used for densified information packaging. As can be seen in example (3), various pre-/post-modifiers (in bold) to noun phrases and a clause (underlined) are used to describe the research purpose. With these elements, the information about research nature, research subjects and research question has been effectively conveyed via one long sentence. Similarly, in example (4), abundant information about research method has been packed in a single long sentence. 
(3) The empirical aim of the study is to describe how counselling conversations are formed, managed and understood by students with migrant background and counsellors, in the course of these conversations.

(SciELF_Ssh68_behaviourial science)

(4) These configurations were generated by imposing no restriction for neither the position nor the length of the gaps, which yielded very complex patterns of missingness.

(SciELF_Sci56_natural science)

In addition, long sentences in ELF research articles contain more phrases (complex nominals, and sometimes coordinate phrases) than clauses, which to some degree further improve the communicative efficiency in written scientific communication. That is, in terms of the number of elements, clauses are more complex than phrases. Therefore, phrases may carry similar amount of information to clauses with fewer words. In other words, the frequent use of complex nominals in long sentences may contribute more to the efficiency of communication and the economy of expression required of a scientific writing than clauses do. For instance, example (5) and (6) are both long sentences used to describe research findings in the field of Medicine, but the former is exacted from an ELF research article while the latter is from an AmE one. It is evident that the two sentences contain similar number of clauses (underlined), but example (5) is much more heavily embedded at phrasal level than example (6). The complex nominals pre-/post-modified by those phrases (in bold) convey comparatively more information, thus more efficient in written communication.

(5) The findings of the study suggest that psychosocial risk factors for carrying a knife, gun, or other weapon, are similar, but that differences in the characteristics of adolescents carrving different types of weapons also exist.

(SciELF_Sci34_medicine)

(6) Our results suggest that it makes sense to differentiate sports and nonsports injuries; whereas the sports unintentional injurer has some problematic risk factors (such as carrying a knife).

(COCA_4119139_medicine)

In a word, the fact that the use of compressed phrasal structures results in even longer sentences may indicate that a great number of phrases are used to improve communication efficiency in ELF research article. In addition, the frequent use of phrases in sentences may lead to a loss of clarity and explicitness in meaning. We will continue discussion on how ELF users deal with this problem in detail in 3.2.2 and 3.2.3.

\subsubsection{Enhance clarity through coordinate phrases with similar meanings.}

In ELF research articles, the syntactic role of coordinate adjectives is most commonly to premodify nouns or noun phrases. Therefore, a great many complex nominals fit into the structure of "coordinate adjectives + noun/noun phrases". Semantically, these coordinate adjectives provide additional information to clarify the quality of the nouns or noun phrases by limiting or restricting and specifying their meaning. For instance, the two adjectives used in the phrases environmental 
and legal scientists help to clarify the scientists' identity by restricting their research areas.

In ELF research articles, coordinate adjectives with a similar meaning are most frequently used as noun premodifiers. This usage, which is especially common in social science and humanities ELF research articles, might be explained as a strategy to enhance clarity. For instance, four pairs of coordinate adjectives (in bold) are used to premodify four different nouns or noun phrases in example (7), and each pair of coordinate adjectives are similar in meaning. Secular and social both indicate that the missions are related to the society. Dominant and directive both underline the leading role of government. Hierarchical and meritocratic both emphasize the elite-dominated system, and institutional and disciplinary both refer to organizational diversity. It can be seen that, as premodifiers, coordinate adjectives with a similar meaning help enhance the clarity of nouns' or noun phrases' meanings by emphasizing their quality.

(7) From a historical perspective, the Chinese model of the university tends to feature ethics-centred exploration of knowledge and normative application, secular and societal missions of higher education, acceptance of the dominant and directive role of government, a vision of teachers and students as scholar-officials or officials in waiting, a hierarchical and meritocratic system, and institutional and disciplinary diversity.

(SciELF_Ssh01_social science)

Similarly, when more than two coordinate adjectives with a similar meaning are used as premodifiers, the quality and meaning of nouns or noun phrases are emphasized and clarified. For instance, in example (8), three coordinate adjectives (in bold), which all carry the meaning of non-rational, are used to premodify the noun lives.

(8) However, the U.S learning model does not seem to evoke passionate affect or to be intimately connected to the emotional, spiritual or moral lives of the respondents.

(SciELF_Ssh02_behaviourial science)

In addition to coordinate adjectives, coordinate nouns or noun phrases with similar meanings are also frequently used in ELF research articles to enhance clarity. For instance, in both example (9) and (10), coordinate nouns or noun phrases are used to list factors; however, the amount of coordinate nouns or noun phrases (underlined) in one sentence from the ELF research article (example (9)) is more than twice the amount of that in the AmE one (example (10)). Further observations reveal that some of the coordinate nouns or noun phrases (e.g. perceived health and weight satisfaction, friendship and intimate relationships) are similar in meaning in example (9). That is, ELF users may use more coordinate nouns or noun phrases for a clarified description of the elements involved.

(9) Self-esteem, perceived health, weight satisfaction, eating habits, physical activity, friendships, intimate relationships, smoking and substance use habits can be regarded as important correlates of psychosocial well-being in adolescence.

(SciELF_Sci35_medicine)

(10) There are individual-based factors such as organizational aptitude and readiness, $\underline{\text { mutual trust and }}$ leadership patterns that actually support the creation of a learning organization and knowledge-based dynamics. 
(COCA_4120007_behavioural science)

\subsubsection{Raise explicitness through noun postmodifiers in complex nominals}

Qualitative analysis reveals that ELF users may raise explicitness through frequent usage of complex nominals postmodified by prepositional phrases. In terms of logic relations, postmodifying prepositional phrases are more explicit than multiple premodifiers in complex nominals. For example, the meaning of corn oil is less explicit than oil from corn, and the expression of lamp oil is less explicit than oil for the use of lamps. With a preposition in between, the internal logical relations of complex nominals become explicit, thus mitigating the burden of meaning processing. For instance, in example (11), six complex nominals (underlined) are postmodified by prepositional phrases (in bold) in one sentence. These prepositional phrases with concrete/abstract or locative meanings not only give more information about the head nouns or noun phrases, but also keep the logical relations between the nouns explicit.

(11) The most common individual indicators measuring innovation capabilities are the research and development expenditures for a given period, investment in new equipment and employee training, percentage of employees trained in the area of innovation, capital invested into the innovation, percentage of staff time devoted to innovation and number of innovative ideas.

(SciELF_Ssh12_social science)

In addition, as postmodifiers to nouns or noun phrases, prepositional phrases are more compressed in structure than clauses but more explicit in meaning than nominal premodifiers. In other words, prepositional phrases postmodifyng nouns or noun phrases could be used as a trade-off to alleviate the tension between the economy of expression (Biber \& Gray 2010) and explicitness of meaning in ELF research articles. For instance, in example (12) and (13), complex nominals (underlined) postmodified by multilayered prepositional phrases may convey similar amount of information with fewer words in comparison to those postmodified by clauses, and they may also be more explicit in meaning relations than those with multiple premodifiers.

(12) The hypothesis that the fitness of organisms in an original habitat without natural enemies should be greater than its fitness in the presence of natural enemies was initially $\langle$ SIC $\rangle$ validate $\langle/$ SIC $\rangle$ for terrestrial insects (e.g. Root, 1973), but also for freshwater zooplankton (e.g. Zaret, 1980) or even for fossil gastropods (Kitchell et al., 1981).

(SciELF_Sci12_natural science)

(13) In 2007 the Act of Canonical Unity between the Moscow Patriarchate and ROCA was signed in Moscow as a symbol of the reunion of both branches of the Russian Orthodox Church.

(SciELF_Ssh57_social science)

\section{Conclusions}

This study has found that although the overall sentence complexity (measured using C/S) shows no difference, there are significant differences across nine indices covering all the four dimensions of syntactic complexity between ELF and AmE research articles, including the length 
of production unit, amount of subordination, amount of coordination, and phrasal complexity. These differences allow us to describe the features of ELF academic writing with regard to syntactic complexity. On average, ELF writers use longer sentences and clauses, more coordination (especially coordinate nouns and coordinate adjectives) but less subordination, and more complex nominal phrases but fewer verbal phrases than their AmE counterparts. We find that some of these complex syntactic structures are preferred over others in order to fulfill particular functions in the formal academic writing in ELF discourse.

The findings that ELF writers use longer sentences than AmE writers echo previous ELF studies that successful communication rather than mastery of native-speaker language use is highly valued in ELF discourse (Björkman, 2013; Cogo, 2012; Jenkins, 2009; Mauranen, 2012; Seidlhofer, 2005, 2011). By employing long sentences, ELF research articles may convey more information, thus achieving an efficient communication. In addition, the present study found that it is embedding at phrasal rather than clausal level that contributes to the use of long sentences in ELF research articles. This finding fits in with previous research by Hundt et al. (2012) who argue that scientific writing is experiencing a shift from more expanded modifications (such as clausal postmodification) to less expanded ones (such as phrasal postmodification).

Furthermore, the frequent use of coordinate phrases (especially coordinate nouns and coordinate adjectives) with similar meanings may help enhance clarity in meaning in ELF research articles. Coordinate adjectives with a similar meaning used to premodify nouns or noun phrases can enhance clarity by limiting, restricting or specifying their qualities. Similarly, coordinate nouns or noun phrases with a similar meaning are also frequently for a clarified description of the elements involved. Therefore, the frequent occurrence of coordination in ELF research articles is not merely a trait of non-native usage of English as suggested by previous research (Mancilla et al., 2015; Ai \& Lu, 2013). Coordinate phrases may also perform special functions (Bell, 2007; Halliday \& Hasan, 2014; Jeremy, 1978) such as enhancing clarity in academic writing in ELF discourse.

Different to most previous studies which claim that academic writing was characterized by more subordinate clauses (Brown \& Yule, 1983; O' Donnell, 1974), the frequent occurrence of complex nominals in the present study is consistent with the research of Biber and Gray (2010), who argue that academic writing is unique in its reliance on nominal/phrasal rather than clausal structures. The most striking use of complex nominals is the ones postmodified by prepositional phrases. It is evidenced in the present study that those postmodifying prepositional phrases can be used to raise explicitness in meaning while still retain a compressed syntactic structure. It should be pointed out that this conclusion is drawn in comparison to those multiple premodifiers in complex nominals, but not to those clausal postmodifers since 'prepositional phrases used as nominal modifiers, (which) are considerably less explicit than alternative clausal modifiers' (Biber \& Gray, 2010: 12). As can be seen in the cline (below) of noun phrase complexity suggested by Biber and Clark (2002), prepositional phrases used as postmodifiers are simpler in terms of the number of elements than clauses, but it appears to be more explicit than multiple premodifiers in terms of meaning.

\begin{tabular}{|c|c|c|c|c|c|}
\hline Compressed & -premodifiers & <phrasal & $<$ non-finite & <relative & -Expanded \\
\hline
\end{tabular}




\begin{tabular}{lcccc}
\hline \hline expression & postmodifiers & clauses & clauses & expression \\
\hline \hline
\end{tabular}

The influence of complex nominals postmodified by prepositional phrases on meaning relations revealed in the present study is interesting in two aspects. First of all, concerning the academic register, it may have repercussion in the shift of scientific writing from the more expanded clausal modification to the less expanded phrasal modification. Compressed structures such as postmodified noun phrases could be explicit in meaning. Therefore, clausal modifications could be replaced by phrasal ones to reduce redundancy, and the less explicit complex nominals such as noun-noun phrases (Biber \& Gray, 2010) could be replaced by postmodified ones to increase explicitness. Second, from an ELF perspective, it provides evidence to support the idea that ELF users desire to raise explicitness through diverse lexico-grammatical features (Mauranen 2012).

The use of complex nominal phrases also reflects that ELF writers stick to the academic conventions. Writing norms in ELF context have been a tricky problem for ELF writers (McCambridge, 2015). On the one hand, ELF in academic writing (especially in research articles for publication in international journals) orients towards a global scholarly world where writers and readers are from various cultural, linguistic and academic backgrounds. In other words, applying the native norms in ELF context is ill-suited. For one thing, applying the native norms makes ELF writers disadvantaged by linguistic deficiency. For another, it may belie the agency of ELF writers as a community in international academic world. On the other hand, as an emerging use of English, ELF is still not mature enough since explicit norms for academic writing have been absent. Under this circumstance, ELF writers may adopt the widely acknowledged conventions such as the use of nominals in academic writing in ELF context. This practice will facilitate establishing explicit writing norms for ELF writers.

The syntactic complexity features in ELF research articles also reflect that ELF writers are trying to handle the two competing goals to achieve effective communication in academic writing: explicitness and conciseness. Given that the present study only makes this inference through the features of syntactic complexity, additional research is needed to investigate how ELF writers manage explicitness of meanings with pragmatic strategies.

\section{References}

Ädel, A., Erman, B., Stockholms, U., Humanistiska, F., \& Engelska, I. (2012). Recurrent word combinations in academic writing by native and non-native speakers of English: A lexical bundles approach. English for Specific Purposes, 31(2), 81-92.

Ai, H., \& Lu, X. (2013). A corpus-based comparison of syntactic complexity in NNS and NS university students' writing. In A. Diaz-Negrillo, N. Ballier \& P. Thompson (Eds.), Automatic Treatment and Analysis of Learner Corpus Data (pp. 249-264). Amsterdam: John Benjamins Publishing Company.

Bell, D. (2007). Sentence-initial 'and' and 'but' in academic writing. Pragmatics, 17(2), 183-201. 
Biber, D., \& Clark, V. (2002). Historical shifts in modification patterns with complex noun phrase structures. In T. Fanego, M. J. López-Couso \& J. Pérez-Guerra (Eds.), English Historical Syntax and Morphology: Selected Papers from 11 ICEHL, Santiago de Compostela, 7-11 September 2000 (pp. 43-66). Amsterdam and Philadelphia: John Benjamins.

Biber, D., \& Conrad, S. (2009). Register, Genre, and Style. Cambridge: Cambridge University Press.

Biber, D., \& Gray, B. (2010). Challenging stereotypes about academic writing: Complexity, elaboration, explicitness. Journal of English for Academic Purposes, 9(1), 2-20.

Björkman, B. (2013). Exploring ELF: Academic English shaped by non-native speakers. ELT Journal, 67(4), 494-497.

Bjork, B.-C., Roos, A., \& Lauri, M. (2009). Scientific journal publishing: Yearly volume and open access availability. Information Research: An International Electronic Journal, 14(1).

Brown, G., \& Yule, G. (1983). Discourse Analysis. Cambridge: Cambridge University Press.

Bulté, B., \& Housen, A. (2012). Defining and operationalising L2 complexity. In A. Housen, \& I. Vedder (Eds), Dimensions of L2 Performance and Proficiency: Complexity, Accuracy and Fluency in SLA (pp.21-46). Amsterdam: John Benjamins.

Bulté, B. \& Housen, A. (2014). Conceptualizing and measuring short-term changes in L2 writing complexity. Journal of Second Language Writing, 26, 42-65.

Bulté, B. \& Housen, A. (2018). Syntactic complexity in L2 writing: Individual pathways and emerging group trends. International Journal of Applied Linguistics, 28(1), 147-164.

Cargill, M., \& O'Connor, P. (2006). Developing Chinese scientists' skills for publishing in English. Journal of English for Academic Purposes, 5(3), 207-221.

Chang, P., \& Schleppegrell, M. (2011). Taking an effective authorial stance in academic writing: Making the linguistic resources explicit for L2 writers in the social sciences. Journal of English for Academic Purposes, 10(3), 140-151.

Chen, Y. H., \& Baker, P. (2010). Lexical bundles in L1 and L2 academic writing. Language Learning \& Technology, 14(2), 30-49.

COCA. (2015). Corpus of Contemporary American English. http://corpus.byu.edu/coca/ Accessed 17 May 2017.

Cogo, A. (2012). English as a lingua franca: Concepts, use, and implications. ELT Journal, 66(1), 97-105.

Cogo, A., \& Dewey M. (2012). Analysing English as a Lingua Franca: A Corpus-Driven Investigation. London: Continuum.

Crossley, S. A., \& McNamara, D. S. (2014). Does writing development equal writing quality? A computational investigation of syntactic complexity in L2 learners. Journal of Second Language Writing, 26, 66-79.

Crystal, D. (2003). English as a Global Language. Cambridge: Cambridge University Press.

Davies, M. (2010). The corpus of contemporary American English as the first reliable monitor corpus of English. Literary and Linguistic Computing, 25(4), 447-464.

Davies, M. (2013). Google scholar and COCA-academic: Two very different approaches to examining academic English. Journal of English for Academic Purposes, 12(3), 155-165

Dolnicar S., \& Chapple, A. (2015). The readability of articles in tourism journals. Annals od Tourism Research, 52, 161-179. 
ELFA. (2008). The Corpus of English as a Lingua Franca in Academic Settings. Director: Anna Mauranen. http://www.helsinki.fi/elfa/elfacorpus/ Accessed 17 May 2017.

Ellis, R. (2009). The differential effects of three types of task planning on the fluency, complexity, and accuracy in L2 oral production. Applied Linguistics, 30(4), 474-509.

Ferris, D. R. (1994). Lexical and syntactic features of ESL writing by students at different levels of L2 proficiency. TESOL Quarterly, 28(2), 414-420.

Firth, A. (1996). The discursive accomplishment of normality: On 'lingua franca' English and conversation analysis. Journal of Pragmatics, 26(2), 237-59.

Flowerdew, J. (2008). Scholarly writers who use English as an additional language: What can Goffman's 'stigma' tell us? Journal of English for Academic Purposes, 7(2), 77-86.

Foster, P., \& Tavakoli, P. (2009). Native speakers and task performance: Comparing effcts on complexity, flency and lexical diversity. Language Learning, 59(4), 866-896.

Granger, S. (1997). On identifying the syntactic and discourse features of participle clauses in academic English: native and non-native writers compared. In A. Jan, I. de Mönnink \& W. Herman. (Eds.), Studies in English Language and Teaching (pp. 185-198). Rodopi: Amsterdam \& Atlanta.

Granger, S., \& Tyson, S. (1996). Connector usage in the English essay writing of native and non native EFL speakers of English. World Englishes, 15(1), 17-27.

Hall, C. M. (2011). Publish and perish? Bibliometric analysis, journal ranking and the assessment of research quality in tourism. Tourism Management, 32, 16-27.

Halliday, M. A. K., \& Hasan, R. (2014). Cohesion in English. London: Routledge.

Halliday, M. A. K., \& Martin, J. R. (2003). Writing Science: Literacy and Discursive Power. Oxford: Taylor \& Francis.

House, J. (2009). Subjectivity in English as lingua franca discourse: The case of 'you know'. Intercultural Pragmatics, 6(2), 171-193.

Hughes, R. (1996). English in Speech and Writing: Investigating Language and Literature. London: Routledge.

Hundt, M. , Denison, D. , \& Schneider, G. . (2012). Relative complexity in scientific discourse. English Language and Linguistics, 16(2), 209-240.

Hyland, K. (2002). Teaching and Researching Writing. England: Longman.

Hyland, K. (2004). Disciplinary interactions: Metadiscourse in L2 postgraduate writing. Journal of Second Language Writing, 13(2), 133-151.

Hyland, K. (2015). Academic Publishing: Issues and Challenges in the Construction of Knowledge. Oxford: Oxford Universiy Press.

Hyland, K. (2016). Academic publishing and the myth of linguistic injustice. Journal of Second Language Writing, 31, 58-69.

Hyland, K., \& Tse, P. (2005). Hooking the reader: A corpus study of evaluative that in abstracts. English for Specific Purposes, 24, 123-139.

Hynninen, N. (2011). The practice of 'mediation' in English as a lingua franca interaction. Journal of Pragmatics, 43(4), 965-977.

Ingvarsdóttir, H., \& Arnbjørnsdottir, B. (2013). ELF and academic writing: A perspective from the expanding circle. Journal of English as a Lingua Franca, 2(1), 123-145. 
Jenkins, J. (2000). The Phonology of English as an International Language. Oxford: Oxford University Press.

Jenkins, J. (2009). English as a lingua franca: Interpretations and attitudes. World English, 28(2), 200-207.

Jenkins, J. (2011). Accommodating (to) ELF in the international university. Journal of Pragmatics, 43(4), 926-936.

Jeremy, R. J. (1978). Use of coordinate sentences with the conjunctionand for describing temporal and locative relations between events. Journal of Psycholinguistic Research, 7(2), 135-150.

Keen, J. (2004). Sentence-combining and redrafting processes in the writing of secondary school students in the UK. Linguistics and Education, 15(1-2), 81-97.

Kusters, W. (2003). Linguistic Complexity : The Influence of Social Change on Verbal Inflection. Utrecht: LOT.

Li, L.-J., \& Ge, G.-C. (2009). Genre analysis: Structural and linguistic evolution of the English-medium medical research article (1985 -2004). English for Specific Purposes, 28(2), 93-104.

Lorés-Sanz, R. (2016). ELF in the making? Simplification and hybridity in abstract writing. Journal of English as a Lingua Franca, 5(1), 53-81.

Lu, X. (2009). Automatic measurement of syntactic complexity in child language acquisition. International Journal of Corpus Linguistics, 14(1), 3-28.

$\mathrm{Lu}, \mathrm{X}$. (2010). Automatic analysis of syntactic complexity in second language writing. International Journal of Corpus Linguistics, 15(4), 474-496.

Luzón, M.-J. (2018). Features of online ELF in research group blogs written by multilingual scholars. Discourse, Context \& Media, 24, 24-32.

Mancilla, R. L., Polat, N., \& Akcay, A. O. (2015). An investigation of native and nonnative English speakers' levels of written syntactic complexity in asynchronous online discussions. Applied Linguistics, 32(2), 1-24.

Martínez, I. A. (2005). Native and non-native writers' use of first person pronouns in the different sections of biology research articles in English. Journal of Second Language Writing, 14(3), 174-190.

Mauranen, A. (1993). Cultural Differences in Academic Rhetoric: A Textlinguistic Study. Frankfurt am Main: Peter Lang.

Mauranen, A. (2003). The corpus of English as lingua franca in academic settings. TESOL Quarterly, 37(3), 513-527.

Mauranen, A. (2009). Chunking in ELF: Expressions for managing interaction. Intercultural Pragmatics, 6(2), 217-233.

Mauranen, A. (2012). Exploring ELF: Academic English Shaped by Non-native Speakers. Cambridge: Cambridge University Press.

Mauranen, A., 2017, Second-order language contact: English as an academic lingua franca. In M. Filppula, J. Klemola \& D. Sharma (Eds.), The Oxford Handbook of World Englishes (pp. 735-753). Oxford and New York: Oxford University Press.

McCambridge, L. (2015). Academic writing in an ELF environment: Standardization, accommodation - or transformation? In T. Lillis, K. Harrington, M. R. Lea \& S. Mitchell (Eds.), Working with 
Academic Literacies: Case Studies towards Transformative Practice (pp. 185-193). South Carolina: Parlor Press.

Milroy, J. \& Milroy, L. (1985). Linguistic changes, social network and speaker innovation. Journal of Linguistics, 21, 339-84.

Mur-Dueñas, P. (2015). Looking into ELF variants: A study of evaluative it-clauses in research articles. Journal of English for Specific Purposes at Tertiary Level, 3(2), 160-179.

Neary-Sundquist, C. (2017). Syntactic complexity at multiple proficiency levels of L2 German speech. International Journal of Applied Linguistics, 27(1), 242-62.

Norris, J. M. \& Ortega L. (2009). Towards an organic approach to investigating CAF in instructed SLA: The case of complexity. Applied Linguistics, 30(4), 555-578.

O' Donnell, R. C. (1974). Syntactic differences between speech and writing. American Speech, 49, 102-110.

Ong, J., \& Zhang, L. J. (2010). Effects of task complexity on the fluency and lexical complexity in EFL students' argumentative writing. Journal of Second Language Writing, 19(4), 218-233.

Ortega, L. (2003). Syntactic complexity measures and their relationship to L2 proficiency: A research synthesis of college - level L2 writing. Applied Linguistics, 24(4), 492-518.

Otto, J., Partow-Navid, P., \& Doshi, M. (2011). Revisiting the readability of management information systems journals again. Research in Higher Education Journal, 15, 77-84.

Pallotti, G. (2014). A simple view of linguistic complexity. Second Language Research, 31(1), 117-134.

Politzer-Ahles, S., Holliday, J. J., Girolamo, T., Spychalska, M., \& Berkson, K. H. (2016). Is linguistic injustice a myth? A response to Hyland (2016). Journal of Second Language Writing, 34, 3-8.

Ranta, E. (2013). Universals in a Universal Language? -Exploring Verb-Syntactic Features in English as a Lingua Franca. (Doctor), University of Tampere, Finland.

Rottensteiner, S. (2010). Structure, function and readability of new textbooks in relation to comprehension. Procedia - Social and Behavioral Sciences, 2(2), 3892-3898.

Sawyer, A., Laran, J., \& Xu, J. (2008). The readability of marketing journals: Are award-winning articles better written? Journal of Marketing, 72(1), 108-117.

Seidlhofer, B. (2004). Research perspectives on teaching English as a lingua franca. Annual Review of Applied Linguistics, 24, 209-239.

Seidlhofer, B. (2005). English as a lingua franca. ELT Journal, 59(4), 339-341.

Seidlhofer, B. (2011). Understanding English as a Lingua Franca. Oxford: Oxford University Press.

Seidlhofer, B., \& Widdowson, H. (2009). Accommodation and the idiom principle in English as a lingua franca. In K. Murata \& J. Jenkins (Eds.), Global Englishes in Asian Contexts: Current and Future Debates (pp. 26-39). London: Palgrave Macmillan.

Swales, J. (1990). Genre Analysis English in Academic and Research Settings. Cambridge \& New York: Cambridge University Press.

Tang, R. (2012). Academic Writing in a Second or Foreign Language: Issues and Challenges Facing ESL/EFL Academic Writers in Higher Education Contexts. New York: Continuum Publishing Corporation

Thomason, S. G. (2001). Language Contact: An Introduction. Washington: Georgetown University Press. 
Trudgill, P. (2009).Sociolinguistic typology and complexification. In S. Geoffery, D. Gil \& P. Trudgill (Eds), Language Complexity as an Evolving Variable (pp. 97-108). Oxford: Oxford Uuniversity Press.

Trudgill P. (2011). Sociolinguistic Typology: Social Determinants of Linguistic Complexity. Oxford: Oxford University Press.

Wells, R. (1960). Nominals and verbal style. In T. A. Sebeok (Ed.), Style in Language (pp.213-220). Cambridge: MIT Press.

Wolfe-Quintero, K., Inagaki, S., \& Kim, H.-Y. (1998). Second Language Development in Writing: Measures of Fluency, Accuracy \& Complexity. Honolulu: University of Hawai'i Press.

WrELFA. (2015). The Corpus of Written English as a Lingua Franca in Academic Settings. Director: Anna Mauranen. Compilation manager: Ray Carey. http://www.helsinki.fi/elfa/wrelfa.html/ Accessed 17 May 2017.

Wright, L. J. (2008). Writing science and objectification: slecting, organizing, and decontextualizing knowledge. Linguistics and Education, 19(3), 265-293.

Zinsser, W. (1988). On writing Well: An Informal Guide to Writing Nonfiction. New York: Harperand Row. 


\section{Acknowledgement}

We would wish to thank the two anonymous reviewers and the journal editors for their helpful suggestions. This research is supported by National Social Science Fund of China [Grant No. 15BYY179] and Provincial Social Science Fund of Hubei [Grant No. 2017085]. 
Xue $\mathrm{Wu}$ is an associate professor of English in School of Foreign Languages at Huazhong University of Science and Technology. Her research interests include corpus linguistics, academic writing, and the use of English as a lingua franca.

Anna Mauranen is a professor of English in the Department of Modern Languages at University of Helsinki. She is the director of the ELFA (English as a lingua franca in academic settings) corpus project, and is one the highly cited authors in English as a lingua franca study.

Lei Lei is a professor of English at the School of Foreign Languages, Huazhong University of Science and Technology. He has published extensively at journals such as Journal of English for Academic purposes, Scientometrics and Journal of Quantitative Linguistics. 